\title{
Korelasi Konflik Kerja Dengan Tingkatan Stres Kerja Pada Perawat Di Rumah Sakit U mum Daerah Petala Bumi Provinsi Riau Tahun 2019
}

\author{
Trisna Jayati \\ Program Studi M agister Kesehatan M asyarakat STIKes H ang Tuah, Pekanbaru, Riau, Indonesia \\ Email : trisnajayati@gmail.com
}

\begin{abstract}
Prolonged stress can have an impact on reducing concentration, nurses become irritable with patients, increase absenteeism, disrupt sleep patterns, and reduce the quality of work by providing nursing care to patients. The purpose of this study was to determine the relationship of work conflict with the level of work stress on nurses at Petala Bumi Regional General Hospital, Riau Province in 2019. The type of research used was observational with analytic crosssectional study design. The sample in this study was 101 nurses. Data analysis was performed univariate, bivariate and multivariate. The results of bivariate research variables work conflict related to the level of work stress are differences of opinion ( $p$ value $=0.002$ ), misunderstanding ( $p$ value $=0.004$ ), feeling disadvantaged ( $p$ value $=0.004$ ) and feeling sensitive ( $p$ value $=0.004$ ). Variables that have a causal relationship with work stress are differences of opinion, misunderstanding, feeling disadvantaged, sensitive feelings. The conclusion in this study is that there is a causal / multivariate relationship between differences of opinion, misunderstanding, feeling disadvantaged, feeling sensitive with an increase in work stress on nurses. It is recommended to the hospital, especially hospital management to take an intensive approach to nurses and supervise so that the source of the difference can be minimized and work that cannot be completed which can lead to disputes that cause stress.
\end{abstract}

Keywords : Job Stress, W ork Conflict, Difference of O pinion, M isunderstanding

\begin{abstract}
ABSTRAK
Stres berkepanjangan dapat berdampak pada penurunan konsentrasi, perawat menjadi mudah marah terhadap pasien, meningkatkan ketidakhadiran kerja, mengganggu pola tidur, dan mengurangi kualitas pekerjaan dengan dalam memberikan asuhan keperawatan terhadap pasien. Tujuan Penelitian ini untuk mengetahui hubungan konflik kerja dengan tingkatan stress kerja pada perawat di Rumah Sakit Umum Daerah Petala Bumi Provinsi Riau Tahun 2019. Jenis Penelitian yang digunakan adalah observasional dengan jenis desain studi penampang analitik (analytic crosssectional study). Sampel dalam penelitian ini adalah 101 perawat. Analisis data dilakukan secara univariat, bivariat dan multivariate. Hasil Penelitian bivariat variabel konflik kerja yang berhubungan dengan tingkatan stress kerja adalah perbedaan pendapat ( $p v a l u e=0,002$ ), salah paham ( $p v a l u e=0,004)$, merasa dirugikan ( $p v a l u e=0,004$ ) dan perasaan sensitive ( $p$ value $=0,004$ ). Variabel yang mempunyai hubungan sebab akibat dengan stress kerja yaitu perbedaan pendapat, salah paham, merasa dirugikan, perasaan sensitive. Kesimpulan dalam penelitian ini adalah terdapat hubungan sebab akibat/multivariate antara perbedaan pendapat, salah paham, merasa dirugikan, perasaan sensitive dengan peningkatan stres kerja pada perawat. Disarankan kepada pi hak rumah sakit khususnya manajemen rumah sakit lebih melakukan pendekatan intensif kepada per awat dan melakukan pengawasan agar sumber perbedaan itu dapat lebih diminimalisirkan dan pekerjaan yang tidak dapat diselesaikan yang dapat mengarahkan pada perselisihan yang mengakibatkan stress.

Kata Kunci: Stres Kerja, Konflik Kerja, Perbedaan Pendapat, Salah Paham
\end{abstract}

Received: 16 October 2019, Accepted : 22 M ay 2020 - M ay 2020 - Jurnal Photon Vol.10 No.2

DOI : https://doi.org/10.37859/jp.v10i2.1544

PHOTON is licensed under a Creative Commons Attribution-ShareAlike 4.0 International License 


\section{Introduction}

Kebutuhan akan layanan kesehatan di rumah sakit membutuhkan sumber daya manusia yang memberikan pelayanan berkualitas. Dalam hal ini, peran perawat menjadi suatu hal yang penting karena berhubungan dengan perkembangan kesehatan pasien. Sekecil apapun kesalahan yang dilakukan perawat dapat berakibat negative terhadap pasien (Husniah, 2015). Stres pekerjaan berdampak pada penurunan perhatian pada orang dengan siapa kita bekerja, keletihan fisik dan emosional. Stres yang berkepanjangan dapat berdampak pada penurunan konsentrasi, perawat menjadi mudah marah terhadap pasien, meningkatkan ketidakhadiran kerja, mengganggu polatidur, dan mengurangi kualitas pekerjaan dengan dalam memberikan asuhan keperawatan terhadap pasien (Hardin, 2015).

Pandangan lama menganggap konflik dalam organisasi sebagai suatu hal yang negative menjurus pada perpecahan organisasi, karena itu harus di hilangkan karena menghambat kinerja optimal. Perselisi han dianggap sebagai indikasi adanya sesuatu yang dianggap sebagai indikasi adanya sesuatu yang salah degan organisasi, dan itu berarti aturanaturan organisasi tidak dijalankan. Pandangan lama selalu mengkhawatirkan keberadaan konflik, maka menjadi tugas pimpinan untk menghindarkan dan bila perlu menghilangkan sama sekali (W ahyudi, 2017). Suatu konflik merupakan hal yang wajar dalam organisasi. Konflik bukanlah menjadi suatu hal yang ditakutkan tetapi merupakan suatu hal yang perlu dikelola agar dapat memberikan kontribusi bagi pencapaian tujuan organisasi. Konflik dapat menjadi energy yang kuat apabila dapat dikelola dengan baik. Jika konflik tidak dapat dikendalikan maka akan mengakibatkan stres pada karyawan yang secara tidak langsung akan berpengaruh terhadap aktivitas organisasi itu sendiri (A nuari, 2017).

Menurut Hany (2011) kurangnya kapasitas perawat dibandingkan jumlah pasien menyebabkan perawat akan mengalami kelelahan dalam bekerja karena kebutuhan pasien terhadap asuhan keperawatan lebih besar dari standar kemampuan perawat. Hal tersebut dibenarkan dengan hasil penelitian Ree dan Cooper (2001) yang menyatakan bahwa perawat memiliki tingkat stres yang lebih tinggi dibanding dengan anggota medislainnya. Keperawatan sebagai pelayanan atau asuhan profesional bersifat humanistik, menggunakan pendekatan holistik, dilakukan berdasarkan ilmu dan kiat keperawatan, berorientasi kepada kebutuhan objektif klien, mengacu pada standar professional keperawatan dan menggunakan etika keperawatan sebagai tuntutan utama. Perawat dituntut untuk selalu melaksanakan asuhan keperawatan dengan benar atau rasional dan baik atau etikal (N ursalam, 2003).H al ini tentu saja merupakan stresor yang cukup besar bagi perawat. Tingkat pendidikan juga dapat mempengaruhi respons tubuh terhadap stresor. Perawat yang bekerja di ruang rawat inap memerlukan pendidikan khusus. Sebagai perawat professional dengan tingkat pendidikan yang lebih tinggi dituntut untuk bisa menjadi panutan bagi tim kerja keperawatan sehingga semakin tinggi pendidikan semakin besar tanggung jawabnya ( $\mathrm{N}$ ursalam, 2003).

Keberadaan profesi perawat sering dianggap biasa saja, walaupun pada kenyataannya peranan perawat dalam pemeliharaan kesehatan sangat vital. Dewasa ini, perawat merupakan segmen profesi terbesar dalam bidang kesehatan.World Health Organization (WHO) melaporkan bahwa sekarang terdapat lebih dari 9 juta perawat dan bidan di 141 negara. Berdasarkan data CDC, jumlah kasus stres kerja yang terjadi di dunia terus mengalami tingkatan setiap tahunnya dari 4409 kasus pada tahun 1998 menjadi 5659 kasus pada tahun 2001 . Berdasarkan survei di Inggris tahun 2014-2015 perawat memiliki tingkat stres kerja tertinggi yaitu 3000 kasus per 100.000 orang yang dipekerjakan (Gupita, 2016). Penelitian yang dilakukan The National Institute Occupational Safety and Health (NIOSH) menunjukkan bahwa pekerjaan-pekerjaan yang berhubungan dengan rumah sakit atau kesehatan memiliki kecenderungan tinggi untuk terkena stres kerja atau depresi, sedangkan American National Association for Occupational Health (ANAOH) menempatkan kejadian stres kerja pada perawat berada diurutan paling atas pada empat puluh pertama kasus stres kerja pada pekerja. M enurut hasil penelitian yang dilakukan oleh Persatuan Perawat Nasional Indonesia (PPNI,2011) mengungkapkan sebanyak 50,9\% perawat Indonesia yang bekerja mengalami stress

Received: 160 ctober 2019, Accepted : 22 M ay 2020 - M ay 2020 - Jurnal Photon Vol.10 No.2

DOI : https://doi.org/10.37859/jp.v10i2.1544

PHOTON is licensed under a Creative Commons Attribution-ShareAlike 4.0 International License 
kerja, sering merasa pusing, lelah, kurang ramah, kurang istirahat akibat beban kerja terlau tinggi serta penghasilan yang tidak memadai yang antara lain dikarenakan beban kerja yang terlalu tinggi dan pekerjaan yang menyita waktu. Jika hal ini dibiarkan tentunya akan menimbulkan dampak yang lebih buruk.

Berdasarkan wawancara peneliti kepada beberapa perawat yang bekerja di Rumah Sakit U mum Petala Bumi, mereka sering mengalami beberapa gejala stres merasa kerja yang dapat mengganggu pelaksanaan kerja mereka seperti: mudah marah, sulit berkonsentrasi pada pekerjaan, merasa lelah dan malas bekerja. Kebanyakan perawat mengalami stres karena memberikan penanganan awal bagi pasien yang menderita sakit dan cedera yang memberikan pelayanan 24 jam. $\mathrm{Hal}$ ini didukung dengan banyaknya pekerjaan yang harus dilakukan, beban kerja perawat yang tinggi, jam kerja yang tinggi, tuntutan pelayanan menjadi perawat professional, sedangkan jumlah perawat pada setiap shifnya sangat minimal. $\mathrm{H}$ al ini disebabkan karena profesi perawat merupakan tenaga kesehatan yang paling tinggi intensitas interaksinya dengan pasien dan sering berhadapan dengan situasi yang dapat menyebabkan terjadinya stres kerja.

Berdasarkan uraian diatas maka peneliti tertarik untuk melakukan penelitian mengenai "Korelasi Konflik Kerja Dengan Tingkatan Stres Kerja Pada Perawat Tujuan penelitian ini adalah untuk mengetahui korelasi konflik kerja dengan tingkatan stres kerja pada perawat di Rumah Sakit Umum Daerah Petala Bumi Provinsi Riau Tahun 2019. Tujuan Penelitian ini adalah untuk mengetahui korelasi konflik kerja dengan tingkatan stres kerja pada perawat di Rumah Sakit U mum Daerah Petala Bumi Provinsi Riau Tahun 2019. Manfaat sosial penelitian ini adalah sebagai masukan bagi pihak rumah sakit untuk mendapatkan informasi dalam tingkatan program pengendalian PAK tentang stres kerja pada perawat di Rumah Sakit Umum Daerah Petala Bumi Provinsi Riau Tahun 2019 dan manfaat ilmiah adalah menambah pengetahuan bagi peneliti lain untuk mengembangkan ilmu khususnya ilmu kesehatan dan keselamatan kerja korelasi konflik kerja berhubungan dengan stres kerja pada perawat.

\section{The M ethods}

Penelitian ini bersifat kuantitatif analitik dengan desain analitik cross sectional. Populasi dalam penelitian ini adalah seluruh Perawat Rawat Inap di Rumah Sakit Petala Bumi yang berjumlah 101 orang.K riteria inklusi yang ditetapkan adalah tenaga perawat yang bekerja di Rumah Sakit Umum Daerah Petala Bumi Provinsi Riau. Responden yang hadir/sehat fisik, jasmani dan rohani saat penelitian. Bersedia menjadi responden penelitian dan mengisi lembar informed consent. Kriteria Eklusi adalah responden yang cuti saat penelitian, responden yang sakit penelitian, perawat tidak bersedia menjadi responden penelitian. Teknik pengambilan sampel dilakukan dengan cara total sampling. Pengumpulan data dalam penelitian ini menggunakan data primer dan sekunder. Data primer diperoleh dengan melakukan wawancara dan observasi dengan menggunakan kuisioner, sedangkan data sekunder diperoleh dari pihak rumah sakit di di Rumah Sakit U mum Daerah Petala Bumi Provinsi Riau. Variabel - variabel yang digunakan adalah tingkatan stress kerja sebagai variabel dependen, sedangkan variabel independen yaitu perbedaan pendapat, salah paham, merasa dirugikan, perasaan sensitive. Pengelolaan data meliputi M enyunting data (Editing), M engkode data (Coding), M emasukkan data (Entry), Membersih data (Cleaning), dan Tabulasi data (Tabulating). Analisis data dilakukan secara univariat, bivariat dilakukan dengan uji Chi Square dan multivariat dengan menggunakan Regresi Logistik Ganda.

\section{Result and Discussion}

\section{Analisis Univariat}

Hasil univariat menunjukkan bahwa sebanyak 53 (52,5\%) perawat Rumah Sakit Petala Bumi Provinsi Riau Tahun 2019 yang mengalami perbedaan pendapat terhadap stress kerja. Sebanyak $52(51,5 \%)$ perawat yang mengalami

Received: 16 October 2019, Accepted : 22 M ay 2020 - M ay 2020 - Jurnal Photon V ol.10 No.2

DOI : https://doi.org/10.37859/jp.v10i2.1544

PHOTON is licensed under a Creative Commons Attribution-ShareAlike 4.0 International License 


\section{http://ejurnal.umri.ac.id/index.php/photon}

selisih paham terhadap stress kerja. Sebanyak 54 (53,5\%) perawat salah satu/kedua belah pihak merasa dirugikan terhadap stress kerja. Sebanyak 53 (52,5\%) perawat yang mengalami perasaan sensitif terhadap stress kerja.

Tabel 1. Distribusi Frekuensi Variabel Independen Konflik Kerja dengan Tingkatan Stres Kerja di Rumah Sakit U mum Daerah Petala Bumi Provinsi Riau Tahun 2019

\begin{tabular}{clcc}
\hline No & \multicolumn{1}{c}{ Variabel } & $\mathrm{n}$ & $\%$ \\
\hline 1. & Stres Kerja & 51 & \\
& Stres Sedang-Berat & 50 & 50,5 \\
& Stres Ringan & & \\
\hline 2. & Perbedaan Pendapat & 53 & 52.5 \\
& Berbeda Pendapat & 48 & 47.5 \\
\hline & Tidak Berbeda Pendapat & & \\
\hline 3. & Berselisih Paham & 52 & 51.5 \\
& Salah Paham & 49 & 48.5 \\
& Tidak Salah Paham & & \\
\hline 4. & Merasa dirugikan & 54 & 53.5 \\
& M erasa Dirugikan & 47 & 46.5 \\
\hline & Tidak M erasa Dirugikan & & \\
\hline 5. & Perasaan Sensitif & 56 & 55.4 \\
& Merasa Sensitif & 45 & 44.6 \\
\hline & Tidak M erasa Sensitif & 101 & $100 \%$ \\
\hline
\end{tabular}

\section{Analisis Bivariat}

Hasil analisis bivariat menunjukkan ada 4 variabel independen yang berhubungan signifikan dengan tingkatan stress kerja yaitu Perawat yang mengalami perbedaan pendapat $3,8(3,889)$ kali lebih beresiko terhadap stres kerja. ( $\mathrm{Cl} 95 \% \mathrm{POR}=1,701-8,888$, perawat yang mengalami salah paham 3,5 $(3,556)$ kali lebih beresiko terhadap stres kerja. ( $\mathrm{Cl} 95 \% \mathrm{POR}=1,566-8,073)$. Perawat yang mengalami merasa dirugikan 3,5 $(3,569)$ kali lebih beresiko terhadap stres kerja. ( $\mathrm{Cl} 95 \% \mathrm{POR}=1,569-8,121)$. Perawat yang mengalami perasaan sensitif 3,6 $(3,600)$ kali lebih beresiko terhadap stres kerja. (Cl 95\%POR=1,575-8,226).

Received: 16 O ctober 2019, Accepted : 22 M ay 2020 - M ay 2020 - Jurnal Photon V ol.10 No.2 DOI : https://doi.org/10.37859/jp.v10i2.1544 
http://ejurnal.umri.ac.id/index.php/photon

Tabel 2. Distribusi Frekuensi Variabel Independen dengan Variabel Dependen di Rumah sakit U mum Daerah Petala Bumi Provinsi Riau Tahun 2019

\begin{tabular}{|c|c|c|c|c|c|c|c|c|}
\hline \multirow{3}{*}{ Konlik Kerja } & \multicolumn{4}{|c|}{ Stres Kerja } & \multicolumn{2}{|c|}{ Total } & \multirow[t]{2}{*}{ Pvalue } & \multirow[t]{2}{*}{$\begin{array}{c}\text { POR } \\
(95 \% \mathrm{Cl})\end{array}$} \\
\hline & \multicolumn{2}{|c|}{$\begin{array}{c}\text { Stres Sedang- } \\
\text { Berat }\end{array}$} & \multicolumn{2}{|c|}{ Stres Ringan } & \multirow[b]{2}{*}{$\mathrm{n}$} & \multirow[b]{2}{*}{$\%$} & & \\
\hline & $\mathrm{n}$ & $\%$ & $\mathrm{n}$ & $\%$ & & & \multirow{4}{*}{0,002} & \multirow{4}{*}{$\begin{array}{c}3,889 \\
(1,701- \\
8,888)\end{array}$} \\
\hline Perbedaan Pendapat & & & & & & & & \\
\hline Berbeda Pendapat & 35 & 66,0 & 18 & 34,0 & 53 & 100 & & \\
\hline Tidak Berbeda Pendapat & 16 & 33,3 & 32 & 66,7 & 48 & 100 & & \\
\hline Berselisih Paham & & & & & & & & 3,556 \\
\hline Salah Paham & 34 & 65,4 & 18 & 34,6 & 52 & 100 & 0,004 & $(1,566-$ \\
\hline Tidak Salah Paham & 17 & 34,7 & 32 & 65,3 & 49 & 100 & & $8,073)$ \\
\hline M erasa Dirugikan & & & & & & & & 3,569 \\
\hline M erasa Dirugikan & 35 & 64,8 & 19 & 35,2 & 54 & 100 & 0,004 & $(1,569-$ \\
\hline Tidak M erasa Dirugikan & 16 & 34,0 & 31 & 66,0 & 47 & 100 & & $8,121)$ \\
\hline Perasaan Sensitif & & & & & & & & 3,600 \\
\hline M erasa Sensitif & 36 & 64,3 & 20 & 35,7 & 56 & 100 & 0,004 & $(1,575-$ \\
\hline Tidak M erasa Sensitif & 15 & 33,3 & 30 & 66,7 & 45 & 100 & & $8,226)$ \\
\hline Total & 51 & 50,5 & 50 & 49,5 & 101 & 100 & & \\
\hline
\end{tabular}

Analisis M ultivariat

Hasil analisis multivariat dapat disimpulkan bahwa variabel yang berhubungan sebab akibat dengan tingkatan stress kerja adalah perbedaan pendapat, salah paham, merasa dirugikan, perasaan sensitive. $\mathrm{H}$ asil Omnibus test of model coeffisient $=0,000$ artinya model yang dihasilkan sudah fit/layak digunakan. Nilai N agelkerke R Square $=0,417$ yang berarti perbedaan pendapat, salah paham, merasa dirugikan, perasaan sensitive dapat menjelaskan tingkatan stress kerja sebanyak $41,7 \%$ sisanya dapat dijelaskan oleh variabel lain yang belum diteliti.

Tabel 3. Pemodelan A khir M ultivariat

\begin{tabular}{clcccc}
\hline No & Konflik Kerja & Pvalue & POR & \multicolumn{2}{c}{ 95\% C.I for EXP (B) } \\
\cline { 4 - 5 } & & & Lower & Upper \\
\hline 1. & Perbedaan Pendapat & 0.004 & 4.329 & 1.609 & 11.651 \\
\hline 2. & Berselisih Paham & 0.003 & 4.766 & 1.730 & 13.131 \\
\hline 3. & Merasa Dirugikan & 0.007 & 3.886 & 1.453 & 10.391 \\
\hline 4. & Perasaan Sensitif & 0.003 & 4.546 & 1.653 & 12.501 \\
\hline
\end{tabular}

Omnibus test of model coefficient $=0,000 \quad$ Nilai nagelkerke $R$ Square $=0,417$

\section{PEMBAHASAN}

Hasil penelitian ini menunjukkan adanya relevansi data karena data yang dikumpulkan, dianalisis dan diinterpretasikan dapat mencapai tujuan khusus dan pembuktian hipotesis. A da validitas Eksternal dalam arti dapat

Received: 160 ctober 2019, Accepted : 22 M ay 2020 - M ay 2020 - Jurnal Photon Vol.10 No.2 DOI : https://doi.org/10.37859/jp.v10i2.1544

PHOTON is licensed under a Creative Commons Attribution-ShareAlike 4.0 International License 
digeneralisasikan ke populasi yang lebih luas, karena menggunakan desain cross sectional, dan data diambil di Rumah Sakit U mum Daerah Petala Bumi Provinsi Riau Tahun 2019. Validitas internal terdiri dari random error penelitian ini dengan sampel 211. Bias seleksi dapat dihindari karena pengumpulan data kepada populasi di Rumah Sakit U mum Daerah Petala Bumi Provinsi Riau Tahun 2019. Bias informasi kemungkinan dapat terjadi dalam pengukuran salah satu variabel independen.

\section{Variabel Yang Berhubungan Dengan Tingkatan Stres Kerja}

a. Hubungan antara Perbedaan Pendapat dengan Tingkatan Stres Kerja

$\mathrm{H}$ asil Penelitian ini menunjukkan bahwa perbedaan pendapat berhubungan secara signifikan dengan tingkatan stress kerja dengan nilai pvalue $\leq 0,005$ yaitu pvalue $=0,02$ ( CI 95\%POR $=1,701-8,888$ ) berati perawat perawat yang mengalami perbedaan pendapat 3,8 kali lebih beresiko terhadap tingkatan stres kerja dibandingkan dengan yang tidak mengalami perbedaan pendapat.

Dalam penelitian ini perbedaan pendapat berhubungan sebab akibat dengan tingkatan stress kerja: perbedaan pendapat lebih berpengaruh dalam tingkatan stres kerja dibandingkan tidak adanya perbedaan pendapat.

Berdasarkan hasil observasi dan wawancara mayoritas responden mengalami perbedaan pendapat. $\mathrm{Hal}$ ini dikarenakan setiap perawat mempunyai pemikiran yang berbeda-beda sehingga adanya ketidaksamaan pemikiran tentang suatu hal atau selera pendapat yang berbeda-beda merupakan hal yang wajar terjadi antar sesama atasan/rekan kerja.

Berdasarkan hasil penelitian ini terdapat persamaan dengan penelitian yang dilakukan penulis dengan teori yang ada, dapat disimpulkan dalam penelitian pada perawat RSU D Petala Bumi Provinsi Riau terdapat masalah yang dialami perawat dalam menjalankan pekerjaaanya. M asalah muncul karena adanya komunikasi yang kurang baik antar atasan/rekan kerja sehingga dapat menimbulkan perbedaan pendapat. Direkomendasikan kepada pihak rumah sakit khususnya manajemen rumah sakit lebih melakukan pendekatan intensif kepada perawat dan melakukan pengawasan kepada perawat agar sumber perbedaan pendapat itu dapat lebih diminimalisirkan.

\section{b. Hubungan antara Berselisih Paham dengan Tingkatan Stres Kerja}

Hasil Penelitian ini menunjukkan bahwa adanya berselisih paham berhubungan secara signifikan dengan tingkatan stress kerja dengan nilai $p$ value $\leq 0,005$ yaitu $p$ value $=0,04$ ( $\mathrm{Cl} 95 \% \mathrm{POR}=1,566-8,073$ ) berati perawat perawat yang mengalami berselisih paham 3,5 kali lebih beresiko terhadap tingkatan stres kerja dibandingkan dengan yang tidak mengalami berselisih paham.

Dalam penelitian ini berselisih paham berhubungan sebab akibat dengan tingkatan stres kerja: berselisih paham lebih berpengaruh dengan tingkatan stres kerja daripada tidak adanya salah paham. Berdasarkan hasil observasi dan wawancara mayoritas responden mengalami salah paham. $\mathrm{Hal}$ ini dikarenakan adanya kesalahan informasi atas pekerjaan yang sama dan dikerjakan secara bersama-sama dan kurangnya pendekatan/ kurang adanya jiwa kebersamaan antar sesama rekan kerja sehingga dapat menimbulkan kesalahpahaman antar sesama perawat.

Berdasarkan hasil penelitian ini terdapat persamaan dengan penelitian yang dilakukan penulis dengan teori yang ada, dapat disimpulkan dalam penelitian pada perawat RSUD Petala Bumi Provinsi Riau terdapat masalah disebabkan karena salah paham diantara atasan/rekan kerja sehingga dapat menimbulkan konflik interpersonal. Konflik interpersonal dalam rumah sakit dapat mempengaruhi tingkat stress apabila konflik tersebut belum diselesaikan dan terus berlangsung pada saat seorang individu berinteraksi dengan tugasnya dan individu lainnya.

Received: 16 October 2019, Accepted : 22 M ay 2020 - M ay 2020 - Jurnal Photon V ol.10 No.2

DOI : https://doi.org/10.37859/jp.v10i2.1544

PHOTON is licensed under a Creative Commons Attribution-ShareAlike 4.0 International License 
Direkomendasikan kepada pihak rumah sakit lebih mengadakan kegiatan bersama ke lapangan atau outbond dalam upaya refreshing untuk mengurangi seringkali munculnya salah paham dalam pekerjaan yang tidak dapat diselesaikan dapat mengarahkan pada perselisihan yang mengakibatkan stress.

\section{c. Hubungan antara M erasa Dirugikan dengan Tingkatan Stres Kerja}

$\mathrm{H}$ asil Penelitian ini menunjukkan bahwa merasa dirugikan kedua belah pihak berhubungan secara signifikan dengan tingkatan stress kerja dengan nilai pvalue $\leq 0,005$ yaitu pvalue $=0,04(\mathrm{Cl} 95 \% \mathrm{POR}=1,569-8,121)$ berati perawat yang merasa dirugikan kedua belah pihak 3,5 kali lebih beresiko terhadap tingkatan stres kerja dibandingkan dengan yang tidak mrasa dirugikann kedua belah pihak.

Dalam penelitian ini, merasa dirugikan kedua belah pihak berhubungan sebab akibat dengan tingkatan stress kerja: merasa dirugikan kedua belah pihak lebih berpengaruh dalam tingkatan stress kerja dibandingkan tidak ada merasa dirugikan. Berdasarkan hasil observasi dan wawancara mayoritas responden masing-masing atau salah satu pihak merasa dirugikan. Hal ini dikarenakan perawat merasa kalau atasan sering memutuskan peraturan rumah sakit/ kesepakatan kerja secara sepihak tanpa transparansi, keputusan tidak sesuai dengan apa yang diharapkan perawat dan keputusan atasan membuat perawat merasa sulit untuk melaksanakannya.

Berdasarkan hasil penelitian ini terdapat persamaan dengan penelitian yang dilakukan penulis dengan teori yang ada, dapat disimpulkan dalam penelitian pada perawat RSU D Petala Bumi Provinsi Riau terdapat konflik terjadi karena masing-masing atau salah satu pihak merasa dirugikan. Kerugian ini bahkan tidak hanya bersifat material melainkan dapat juga non material. Stres kerja dapat mengganggu bahakan merugikan diri sendiri sebagai peribadi dan dapat merugikan rumah sakit pula. Secara kasat mata konflik tidak bisa terlihat jelas tetapi mugkin hanya gejala-gejala saja yang dapt ditemukan di rumah sakit mengakibatkan berkurangnya kepuasan dari perawat dan menurunkan semangat kerja sehingga meningkatnya kemangkiran/absensi.

Direkomendasikan kepada perawat berusaha agar mampu mentoleransi stess dan memperkuat sikap/sifat agar lebih tahan dalam menghadapi konflik sesuai dengan apa yang diharapkan perawat, maka akan berdampak pada meminimalisisr stress kerja.

\section{d. Hubungan antara Perasaan Sensitif dengan Tingkatan Stres Kerja}

$\mathrm{H}$ asil Penelitian ini menunjukkan bahwa mengalami perasaan sensitive berhubungan secara signifikan dengan tingkatan stress kerja dengan nilai pvalue $\leq 0,005$ yaitu pvalue $=0,04(\mathrm{Cl} 95 \% \mathrm{POR}=1,575-8,226)$ berati perawat yang mengalami perasaan sensitive 3,6 kali lebih beresiko terhadap tingkatan stres kerja dibandingkan dengan yang tidak mengalami perasaan sensitive. Dalam penelitian ini, perasaan sensitif berhubungan sebab akibat dengan tingkatan stress kerja: merasa sensitif berpengaruh dalam tingkatan stress kerja dibandingkan tidak ada merasa sensitif.

Berdasarkan hasil observasi dan wawancara mayoritas responden mengalami perasaan sensitive. $\mathrm{Hal}$ ini bisa dikarenakan adanya kecemburuan sosial antar sesama rekan kerja seperti iri karena karyawan yang lain lebih diperhatikan oleh atasan atau memang adanya rasa tidak suka terhadap rekan kerja yang lain dan rasa tidak setuju dengan sikap kerja yang terlihat. Berdasarkan hasil penelitian ini terdapat persamaan dengan penelitian yang dilakukan penulis dengan teori yang ada, dapat disimpulkan dalam penelitian pada perawat RSUD Petala Bumi Provinsi Riau terdapat masalah yang terjadi antar atasan atau rekan kerja yang tidak dapat dihindari. Konfik kerja seperti ini biasanya mempunyai sifat yang tersembunyi. Konflik ini biasanya terjadi secara tidak sadar yang dapat mengganggu tingkat stress kerja dilihat dari gejala fisiologis, gejala psikologis, dan gejala perilaku. Hal ini dapat mengakibatkan konflik menjadi besar serta dapat mengganggu jalannya kegiatan. Direkomendasikan kepada

Received: 16 October 2019, Accepted : 22 M ay 2020 - M ay 2020 - Jurnal Photon V ol.10 No.2

DOI : https://doi.org/10.37859/jp.v10i2.1544

PHOTON is licensed under a Creative Commons Attribution-ShareAlike 4.0 International License 
perawat pada pendekatan individual dapat berusaha sendiri untuk mengurangi level stresnya yaitu dengan pengelooan waktu, latihan fisik, latihan relaksasi, dan dukungan sosial.

\section{KESIM PULAN}

Berdasarkan uraian pada hasil penelitian dan pembahasan maka dengan ini penelitian mengambil kesimpulan sebagai berikut:

1. Proporsi perawat Rumah Sakit Petala Bumi Provinsi Riau mengalami konflik kerja adalah sebesar 50.5\%pada stress sedang-berat

2. Variabel independen yang berhubungan sebab akibat dengan tingkatan stress kerja adal ah sebagai berikut:

a. Perawat yang mengalami beda pendapat $3,8(3,889)$ kali lebih beresiko terhadap stres kerja dibandingkan dengan perawat yang tidak mengalami beda pendapat.

b. Perawat yang mengalami salah paham $3,5(3,556)$ kali lebih beresiko terhadap stres kerja dibandingkan dengan perawat yang tidak mengalami salah paham.

c. Perawat yang mengalami merasa dirugikan 3,5 $(3,569)$ kali lebih beresiko terhadap stres kerja dibandingkan dengan perawat yang tidak merasa dirugikan.

d. Perawat yang mengalami perasaan sensitif 3,6 $(3,600)$ kali lebih beresiko terhadap stres kerja dibandingkan dengan perawat yang tidak mengalami perasaan sensitive.

3. Faktor konflik kerja lebih dominan yang dapat beresiko terjadinya stress kerja adalah perbedaan pendapat ( $p v a / u e=0,002$ ) dan 3,8 kali dengan stress kerja pada perawat di Rumah Sakit U mum Daerah Petala Bumi Provinsi Riau Tahun 2019.

\section{References}

Anuari. 2017. Pengaruh Konflik Kerja Terhadap Stres Kerja Dan Motivasi Kerja Serta Dampaknya Terhadap Komitmen Organisasional. Jurnal diakses M ei 2019.

Aswan, A hmad W aruwu. 2018. Pengaruh Kepemimpinan, Stres Kerja dan Konflik Kerja Terhadap Kepuasan Kerja Serta Dampaknya Kepada Kinerja Pegawai Sekretariat DPRD Provinsi Sumatera Utara. Jurnal Diakses Juli 2019.

Daniel Tarigan, Sangap. 2012. Hubungan Beberapa Faktor Dengan Stres Kerja Pada Pegawai Lembaga Kemasyarakatan Pekanbaru Tahun 2012. Tesis Program Pasca Sajana IImu kesehatan M asyarakat. Sekolah Tinggi IImu Kesehatan H ang Tuah Pekanbaru.

Departemen Kesehatan RI.Undang-U ndang N o.36 Tahun 2009 tentang Kesehatan.Jakartra; Departemen Kesehatan $\mathrm{RI} ; 2009$.

Depkes RI.2005.U ndang-U ndang Republik Indonesia N omor:23 Tahun 2005 Tentang Kesehatan; Jakarta.

Ekawarna.2018. Manajemen Konflik dan Stres. Rawamangun.PT Bumi A ksara

Fitriani.2011."Faktor-Faktor Yang Berhubungan Dengan Stress Kerja Perawat DiRuang Rawat Inap RSI Faisal".Skripsi Fakultas Kesehatan UIN Alauddin M akassar

Glandy, M iracle.2017.Pengaruh Konflik Terhadap Kinerja Karyawan pada PT.Pengadaian (Persero) Manado. Jurnal Diakses Juli 2019

H awari, D adang. 2006. Manajement Stres, Cemas, dan Depresi: J akarta Gaya

Health and Safety Executive.Work Related Stress Anxiety and Depression Statistic in Great Britain 2015; 2015. Diperoleh tanggal 28 Januari 2019, dari http://www.hse.gov.uk/statistics/causdis/stress/stress.pdf

Received: 16 October 2019, Accepted : 22 M ay 2020 - M ay 2020 - Jurnal Photon V ol.10 No.2

DOI : https://doi.org/10.37859/jp.v10i2.1544

PHOTON is licensed under a Creative Commons Attribution-ShareAlike 4.0 International License 
Husniah, A eni. 2015. Pengaruh Konflik Pekerjaan Keluaega dan Stres Kerja Terhadap Kepuasan Kerja Perawat RS PKU M uhammadiyah Yogyakarta.Jurnal diakses M ei 2019

Irwan, Muhammad. Pengaruh Stres dan Konflik Kerja Terhadap Kinerja Karyawan PT.Kalla Kakao Industri Kota Makassar. Jurnal Diakses Juli 2019

Lapau, Buchari. 2010. M etodologi Penelitian Kesehatan.Jakarta.

M aulana.2015. Pengaruh Konflik dan Lingkungan Kerja Terhadap Kinerja Karyawan. Fakultas Ekonomi. Universitas N egeri Semarang..Jurnal Diakses Juli 2019

M artina.A.(2012). Gambaran Tingkat Stress Kerja Perawat Di Ruang Rawat Inap Rumah Sakit Paru Dr. M oehammad Goenawan Partowidigo Cisarua Bogor (RSPG).Skripsi Fakultas IImu Keperawatan U niversitas Indonesia.

Mitra.(2015). Manajemen dan A nalisis Data Kesehatan.(Andi. Ed). Yogyakarta

Nitisemito A lex S., 2001, M anajemen Personalia (Sumber Daya M anusia), Bumi Aksara, Jakarta

N otoadmodjo,S.2007.I/mu Kesehatan M asyarakat.J akarta:Rineka Cipta

Nurazizah,2017.Faktor -Faktor Yang Berhubungan Dengan Stres Kerja Pada Perawat di Ruang Rawat Inap Kelas I/I RS X Jakarta Tahun 2017.Fakultas Kedokteran dan IImu Kesehatan Universitas Islam Negeri Syarif Hidayatullah Jakarta.Skripsi

Nursalam.(2003).Konsep Dan Penerapan Metodologi Penelitian I/mu Keperawatan:Pedoman Skripsi, Tesis, Dan Instrument Penelitian.Jakarta:Salemba M edika.

Persatuan Perawat Nasional Indonesia (PPNI).(2006). Survei Stress Kerja Perawat

Priyo H artono, Sutanto. 2016. Analisis Data Bidang Kesehatan Jakarta.PT Raja Grafindo Persada

Priyoto.2014. Konsep Manajemen Stress.Yogyakarta. Nuha M edika

Puji, Pratiwi Lestari.2013. Faktor-Faktor Yang Berhubungan Dengan Stres Kerja Pada Wanita Bekerja Sektor Formal Di Wilayah Kecamatan Ciputat Timur Tahun 2013. Fakultas Kedokteran dan IImu Kesehatan Universitas Islam Negeri Syarif Hidayatullah Jakarta.Skripsi

Rosihan, Rian Ansori. 2017. Hubungan Faktor Karakteristik Individu dan Kondisi Pekerjaan terhadap Stres Kerja Pada Perawat Gigi. Jurnal diakses Juli 2019.

Russeng, syamsiar dkk. 2007 Stres kerja pada perawat di instalasi rawat inap Rumah Sakit Dr. Tadjudin Chalid Makasar .jurnal diakses pada Februari 2019.

Sedarmayanti.2001.Sumber Daya M anusia dan produktivitas Kerja.Bandung:M andar M aju.

Tarwaka.2011.Ergonomi Untuk Keselamatan, Kesehatan Kerja dan Produktifitas. Surakarta:U niba Press.

Undang-undang N omor 13 Tahun 2003 Tentang Ketenagakerjaan

Wahudi.2017. Manajemen Konflik dan Stres dalam Organisasi. Bandung. Alfabeta

Yana, D ewi.2014.Stres Kerja Pada Perawat Instalasi Gawat Darurat RSU D Pasar Rebo Tahun 017. Jurnal Diakses A pril 2019

Received: 16 October 2019, Accepted : 22 M ay 2020 - M ay 2020 - Jurnal Photon Vol.10 No.2

DOI : https://doi.org/10.37859/jp.v10i2.1544

PHOTON is licensed under a Creative Commons Attribution-ShareAlike 4.0 International License 